\title{
URBANIZACIÓN Y ACCESO DE LOS SECTORES POPULARES AL SUELO URBANO EN LA CIUDAD DE CÓRDOBA (ARGENTINA). POLÍTICAS DE ESTADO Y ESPACIOS EN TENSIÓN ${ }^{1}$
}

\section{DEVELOPMENT AND POPULAR ACCESS TO URBAN LAND AREAS IN THE CITY OF CORDOBA (ARGENTINA). STATE POLICIES AND SPACES IN TENSION}

\section{Carla Eleonora Pedrazzani² Paula Andrea Pedrazzani ${ }^{3}$}

\section{Resumen}

El modelo de producción hegemónico (el capitalista) opera de forma multiescalar, multidimensional y geopolítica. Transformaciones en la economía, en lo social y lo político a escala global (mundial) repercuten en múltiples escalas geográficas. Determinados espacios, territorios y lugares son reconfigurados en pos de la acumulación de capital y de intereses estratégicos para la reproducción de este modelo. Los espacios urbanos, las ciudades son producto y resultado de la interacción de diversas lógicas de producción y apropiación del espacio que se encuentran en relación con dicho modelo socioeconómico dominante. La ciudad de Córdoba no es ajena a los procesos globales de acuerdo a los cuales existe una predominancia de la mundialización de la economía capitalista y bajo la cual se han producido fuertes procesos de restructuración económica-productiva junto con la consolidación de políticas neoliberales y postneoliberales. El abordaje que proponemos se plantea como una reflexión crítica respecto a las lógicas de producción y apropiación del espacio urbano para (repensando el accionar estatal desde las políticas de vivienda social) y por parte (desde la autoproducción) de los sectores populares. Este trabajo se basa en los resultados de investigaciones empíricas anteriores, desarrolladas mediante una metodología cualitativa junto con la utilización de diversas fuentes secundarias y material bibliográfico.

Palabras claves: producción del espacio urbano, políticas del Estado, acceso al suelo, sectores populares

\begin{abstract}
The hegemonic model of production (capitalist) operates in a multi-scale, multi-dimensional and geopolitics way. Transformations in the economy, the social and the political in global scale affect multiple geographical scales. Certain spaces, territories and locations are reconfigured towards capital accumulation and strategic interests for reproduction of this model. Urban areas, cities are product and result of interaction of various logics of production and appropriation of space found in connection with such dominant economic model. Cordoba city is no stranger to global processes according to which there is a predominance of the globalization of the capitalist economy and under which there have been sharp processes of economic-productive restructuring together with the consolidation of neoliberal and post neoliberal policies. The approach we propose is seen as a critical reflection on the logic of production and appropriation of urban space (rethinking state action from the social housing policies) and by (from autoproduction) the popular sectors. This work is based on the results of previous empirical research, developed through a qualitative methodology with the use of various secondary sources and bibliographical material.
\end{abstract}

Keywords: production, state policies, access to land, urban space, popular sector

\footnotetext{
${ }^{1}$ Una versión anterior de este trabajo ha sido presentada como trabajo en extenso bajo el nombre de "Urbanización y políticas de estado. La ciudad de Córdoba (Argentina), espacios en disputa y acceso de los sectores populares al suelo urbano" en el XV Encuentro de Geógrafos de América Latina. Por una América Latina unida y sustentable, La Habana (Cuba) 2015.

${ }^{2}$ Becaria doctoral de CONICET/IIFAP en la Universidad Nacional de Córdoba. E-mail: pedroavz@gmail.com

${ }^{3}$ Profesora contratada de la Universidad Nacional de Córdoba. E-mail: paulapedrazzani@yahoo.com.ar
} 


\section{INTRODUCCIÓN}

El modelo de producción hegemónico (el capitalista) opera de forma multiescalar, multidimensional y geopolítica. Transformaciones en la economía, en lo social y lo político a escala global (mundial) repercuten en múltiples escalas geográficas. Determinados espacios, territorios y lugares son reconfigurados en pos de la acumulación de capital y de intereses estratégicos para la reproducción de este modelo. Como plantea Harvey "la política del capitalismo se ve afectada por la perpetua necesidad de encontrar campos rentables para la producción y absorción de un excedente de capital" (Harvey, 2012: 22). En ese proceso, la ciudad de Córdoba no es ajena a los procesos globales de acuerdo a los cuales existe una predominancia de la mundialización de la economía capitalista y bajo la cual se han producido fuertes procesos de restructuración económica-productiva junto con la consolidación de políticas neoliberales y postneoliberales. En las últimas décadas -particularmente desde los años 90'- tanto la construcción como especulación inmobiliaria en el marco del mercado formal ha adquirido fuerza y dinamismo en la producción de la ciudad, disputando espacios, territorios y el suelo urbano en diversas áreas. La ciudad ha sido y es hoy un espacio en disputa por una heterogeneidad de actores, sujetos, grupos y sus lógicas. Diversos autores plantean que la forma de acceso al suelo urbano de los sectores populares puede ser comprendida a partir de tres lógicas de producción y apropiación del espacio urbano que interactúan de manera compleja y contradictoria: la lógica de la ganancia -ciudad como objeto y soporte de negocios-, la lógica de la necesidad - impulsada por aquellos sectores que no logran acceder a las condiciones de reproducción social en el marco de la regularidad urbana-, y la lógica de lo público o del estado - donde por medio de distintas intervenciones en materia de políticas, el estado provee el sustento para el despliegue y desarrollo de las otras lógicas (Herzer et al, 1994; Rodríguez, 2007; Abramo, 2009). Al igual que sucede en otras ciudades de Argentina como de Latinoamérica, en la ciudad de Córdoba la producción del espacio urbano hegemónica está dada por una lógica de captura de ganancias y rentabilidad económica. El espacio urbano se vuelve un "negocio", una mercancía en disputa por diversos grupos y actores, donde otras formas o lógicas de producción y reproducción de la ciudad quedan relegadas a ciertas zonas de la ciudad y muchas veces catalogadas como lo "irregular", "informal" e "ilegal". Lo que rige, entonces, es la competitividad urbana como ideología y en ese contexto la centralidad de la ciudad y la vida urbana no es para TODO/AS; lo es solamente para quienes tienen el poder y los recursos de imponer su visión de orden urbano, de progreso y de desarrollo. Y como contraparte de este proceso, un gran contingente de población "no puede acceder a las 
viviendas construidas por el sector privado y no encuentra una alternativa en las iniciativas del sector público" (Trivelli, 1982: 8), ya que muchas veces no cuentan con recursos propios ni pueden acceder a financiamientos del sector financiero y se enfrentan a problemas vinculados a dificultades para organizarse como grupo y pocas posibilidades de participación en la definición de alternativas de políticas, presentándose entonces un esquema atomizado en el que quedan pocas opciones de accesibilidad a soluciones habitacionales de forma individual (Trivelli, 1982), al suelo urbano como propietario y a la propia ciudad.

De acuerdo al Censo Provincial de Población del año 2008, el departamento Capital posee un total de 1.315.423 habitantes y de acuerdo al Censo Nacional de Población, Hogares y Vivienda del año 2010 un total 1.330.023 de habitantes. Respecto a la vivienda, la Dirección de Estadísticas y Censos de la provincia publicó el dato de que para toda la provincia la cantidad de hogares por vivienda (que albergan más de un hogar) se incrementó desde el año 2001 al 2008.

Tabla 1. Viviendas y cantidad de hogares

\begin{tabular}{|c|c|c|c|c|c|c|c|c|c|c|c|}
\hline \multicolumn{7}{|c|}{ Viviendas, hogares y personas. } & \multicolumn{5}{|c|}{$\begin{array}{c}\text { Cantidad de hogares } \\
\text { wor vivienda }\end{array}$} \\
\hline $\begin{array}{l}\text { Provincia } \\
\text { de } \\
\text { Córdoba }\end{array}$ & $\begin{array}{l}\text { Viviendas } \\
\text { particulares }\end{array}$ & $\begin{array}{l}\text { Viviendas } \\
\text { particulares } \\
\text { coupadas }\end{array}$ & Hogares & $\begin{array}{l}\text { Población } \\
\text { Total }\end{array}$ & $\begin{array}{c}\text { Población } \\
\text { en } \\
\text { hogares }\end{array}$ & $\begin{array}{c}\text { Tamaŕo } \\
\text { promedio } \\
\text { del hogar } \\
\text { (*) }\end{array}$ & $\begin{array}{l}\text { Promedio } \\
\text { de hogares } \\
\text { por } \\
\text { vivienda }\end{array}$ & $\begin{array}{l}\text { Provincia } \\
\text { de } \\
\text { Cóndoba }\end{array}$ & 1 & 2 & $\begin{array}{l}30 \\
\text { más }\end{array}$ \\
\hline $\begin{array}{l}\text { Total } \\
2008\end{array}$ & 1.195690 & 960.438 & 1.010 .500 & 3243.621 & 3.200 .229 & 3,2 & 1,05 & $2000 \%$ & 91,1 & 3,3 & \\
\hline $\begin{array}{l}\text { Total } \\
2001\end{array}$ & 1.060029 & 849670 & 877.252 & 3066.801 & 3.028 .943 & 3,5 & 1,03 & $2001 \%$ & 94,0 & 2,4 & 3,6 \\
\hline
\end{tabular}

(*) Número promedio de miembros por hogar

Fuente: Dirección General de Estadísticas y Censos. Gobierno de la provincia de Córdoba.

En esta línea, la Red Ciudadana Nuestra Córdoba ${ }^{4}$ a través del estudio de diversos indicadores en torno al desarrollo urbano y la vivienda para el departamento capital (con referencia a los datos del Censo Provincial 2008) plantea que el déficit habitacional cuantitativo es de 29121 en lo que respecta a vivienda compartida por más de un hogar y 12156 por tipología de vivienda. Y en cuanto al déficit cualitativo, hay 3854 viviendas con ausencia de baño, un 1,9\% de la población total vive en viviendas precarias (no son casas tipo A ni departamentos) y el 7,8\% del total de personas se encuentra en situación de hacinamiento (3 y más personas por cuarto).

Estos datos dan cuenta: por un lado, de la complejidad de situaciones y dificultades existentes en torno a la problemática de acceso al suelo urbano por parte de los sectores

\footnotetext{
${ }^{4}$ Red que nuclea a organizaciones sociales, universidades, empresas, centros de investigación, colegios profesionales, ciudadanos y ciudadanas de la Ciudad de Córdoba. Es un ámbito de acción colectiva plural, no partidario, autónomo de los gobiernos en todos sus niveles y abierto a todas las personas y organizaciones que compartan sus principios y objetivos y estén dispuestas a contribuir a su realización. http://www.nuestracordoba.org.ar.
} 
populares en la ciudad de Córdoba; y por el otro, de la necesidad de realizar un abordaje integral en torno a la temática en donde se puedan analizar los procesos, condiciones y situaciones de inserción sociopolítica y territorial de accesibilidad al suelo urbano por parte de los sectores populares, y se los comprenda en relación a la ciudad como totalidad.

El abordaje que proponemos aquí se plantea como una reflexión crítica respecto a las lógicas de producción y apropiación del espacio urbano para (repensando el accionar estatal desde las políticas de vivienda social) y por parte (desde la autoproducción) de los sectores populares. Se estructura en relación a dos objetivos: problematizar la orientación de las políticas habitacionales y urbanas en cuanto lógica de producción de espacio urbano en la ciudad; y aportar elementos de análisis en torno a la problemática del acceso a la vivienda y la ciudad de los sectores populares.

Este trabajo se basa en los resultados de investigaciones empíricas anteriores, desarrolladas mediante una metodología cualitativa junto con la utilización de diversas fuentes secundarias y material bibliográfico sobre la temática.

Imagen I. Localización de la ciudad de Córdoba-Argentina

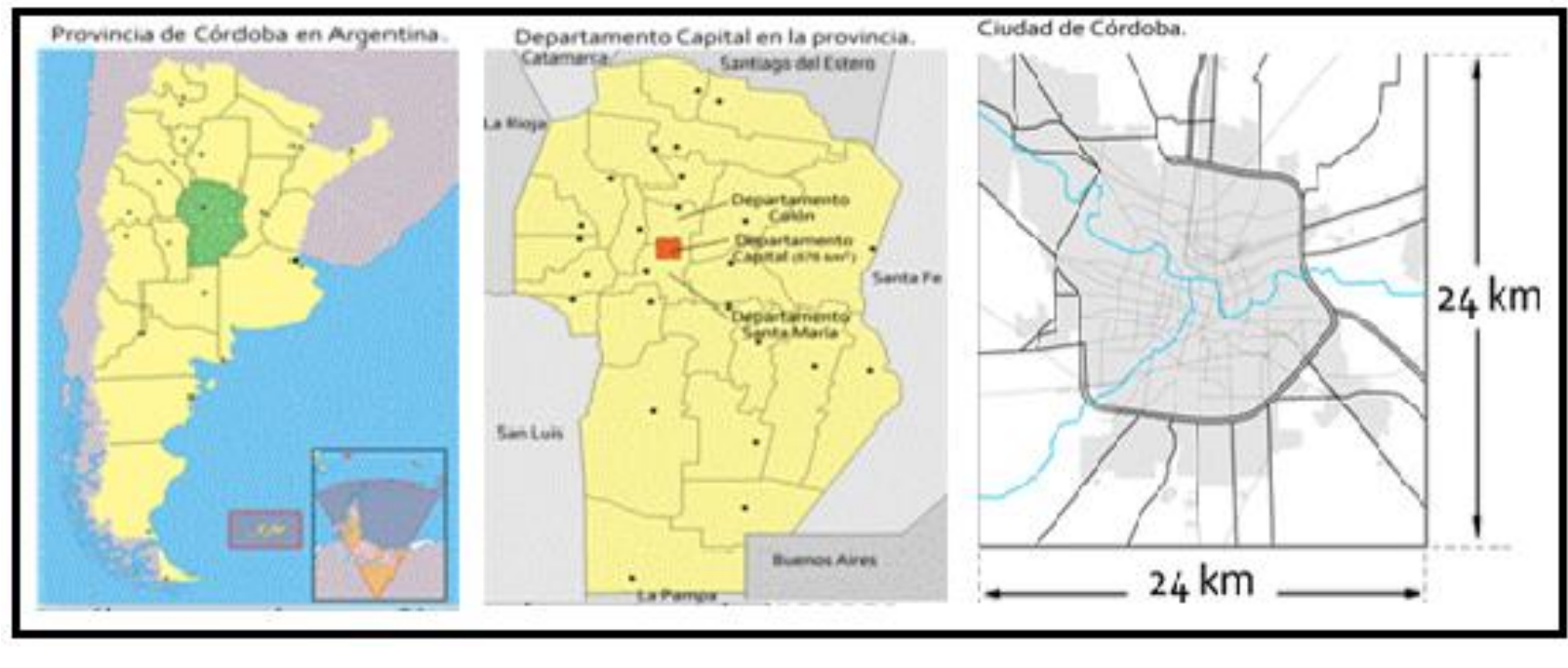

Fuente: SAAP (Sociedad Argentina de Análisis Político). Disponible en: http://www.saap.org.ar/esp/page.php?subsec=congresos\&page=congresossaap/decimo\&data=X/cordoba.

\section{BREVES CONSIDERACIONES TEÓRICAS Y POSICIONAMIENTO}

Respecto a las consideraciones teóricas y nuestro posicionamiento, es preciso aclarar que se trata de un planteamiento en el que se retoman y articulan teorías sociales y aportes que aún siguen vigentes sobre el papel de espacio en la producción y reproducción de la sociedad y (re)pensarlo para el caso de la Ciudad de Córdoba; particularmente en torno a los 
sectores populares. Es decir, recuperar ciertos esquemas interpretativos y armar un esquema propio de análisis para el contexto del objeto de estudio.

Consideramos que los aportes realizados desde otros campos y disciplinas, especialmente desde la propia Geografía son fundamentales para la elaboración de una propuesta de análisis; sin embargo, como plantea Pradilla Cobos (2009) no se puede dar por supuesta la validez de conceptos y abordajes para toda realidad (barrial, local, urbana, regional, nacional, etc.) sin ninguna crítica ni adaptación a las propias realidades de análisis y a las realidades latinoamericanas. Es necesario un proceso de particularización repensándolos para los casos y realidades que se aborden. Por lo cual, es necesario un esfuerzo crítico y no un uso popularizado de los conceptos.

Si bien las ciudades, en Latinoamérica pueden tener un proceso histórico de producción, reproducción, cambio y transformación social con un patrón semejante. Cada espacio, territorio y ciudad posee ciertas particularidades que le son propias a la coyuntura social, política, económica, cultural y espacial. Y por sobre todo a la forma y contenido en que se producen y reproducen las relaciones sociales y las prácticas socioespaciales en las diversas escalas y dimensiones que puedan presentarse para el análisis. Los sectores populares en Ecuador, en Colombia, en Brasil, en Perú, en Bolivia, Uruguay o Argentina no están conformados necesariamente por los mismos sujetos histórico-políticos. Caso semejante sucede con las modalidades de producción de espacio urbano a través de las distintas tipologías de asentamientos humanos. Por lo cual, los abordajes ha de ser pensados necesariamente para y en el marco del contexto en el que se están produciendo, teniendo en cuenta sus múltiples escalas, dimensiones y relaciones. Lo cual no significa dejar de lado esquemas interpretativos generales, pero sí que cuenten con una adecuación en vínculo a lo concreto.

\section{PRODUCCIÓN DEL ESPACIO URBANO}

Si pretendemos realizar una reflexión crítica respecto a las lógicas de producción y apropiación del espacio urbano, es preciso dar cuenta -al menos brevemente- desde donde estamos pensando la producción del espacio. Si hacemos un recorrido por ciencias sociales, el espacio ha sido y es un concepto con múltiples acepciones. A finales de la década de los 60' y principios de los 70', en el marco de la nueva sociología urbana francesa, se produce un giro en torno a la concepción del espacio en la cual se propone una nueva relación de éste con la sociedad. Lefebvre $(1969,1976)$, como uno de sus principales exponentes, plantea al espacio como un producto social en cuya base ontológica espacio y sociedad se construyen mutuamente. La producción del espacio pasa a constituirse dentro de los análisis como 
resultado y medio, producto y trabajo. El ser es social, espacial e histórico; por lo cual, se pone en juego una dialéctica intrínseca entre estas dimensiones. El espacio, entonces, es considerado como una construcción histórica-social en relación a un modo de producción y a una formación social. En él, no sólo se van a proyectar las relaciones sociales; sino que se va a inscribir a sí mismas en éste a medida que se producen (Lefebvre, 1976). Vinculado a ello, se replantea también la asociación del espacio con el tiempo a partir de una concepción relacional en la cual cada proceso produce su propio espacio-tiempo; y en donde existen distintas visiones de ambos que entran en conflicto entre sí (Harvey, 1994). Esta ruptura con concepciones absolutas (teorías Newtoniana) y también las relativas (Einstein), posibilita el pensamiento de la construcción social del espacio y tiempo. A partir de aquí, diversos autores desde la Geografía Crítica (Harvey, Santos, Soja, Alessandri Carlos, entre otros) apuestan a la construcción de una teoría sobre la producción del espacio en vinculación al materialismo histórico en donde tanto espacio como espacialidad se co-constituyen con lo social (Soja, 1985). El espacio “... es visto completamente atravesado y constituido por las relaciones social-históricas, o, de modo más estricto, según muchos autores, relaciones de poder" (Haesbaert, 2007).

Esta concepción acerca del espacio y su producción, nos ofrece un posicionamiento mediante el cual se pueden pensar y analizar diversas lógicas de producción de la ciudad como parte de la producción del espacio urbano y como una forma de producción de la sociedad en el movimiento histórico de su reproducción. Como plantea Abramo (2009), en las realidades latinoamericanas no es posible comprender la producción de nuestras ciudades si consideramos únicamente el mercado inmobiliario regulado por los derechos formales y los programas y políticas de gobierno. "La ciudad popular nace y se reproduce como una respuesta a la norespuesta de las formas estatales y mercantiles de provisión de hábitat urbano. Los sectores populares, movidos por la lógica de la necesidad, se inventan mecanismos de producción de la ciudad y de reproducción de nuevos hábitat urbanos independientes de los condicionamientos establecidos por los derechos de propiedad, urbanísticos y comerciales que regulan la vida urbana del estado de derecho" (Abramo, 2009: 22), siendo esta forma de producción un parte constitutiva de las ciudades y éstas no pueden ser entendidas sin la incorporación de las urbanizaciones populares al análisis.

Asimismo, en el abordaje que planteamos, las políticas habitacionales y urbanas se vuelven también un elemento central del análisis. Tomamos aquí la definición de Oszlak y O' Donnell (1984) en relación a las políticas públicas o estatales dado que consideramos que permite poner de manifiesto una complejidad de aspectos y dimensiones que no son tenidos en cuenta en otras definiciones, como así también poner atención a la interacción de distintos 
actores en la definición de qué es una política. Para estos autores, las políticas públicas son definidas como "un conjunto de acciones y omisiones que manifiestan una determinada modalidad de intervención del Estado en relación con una cuestión que concita la atención, interés o movilización de otros actores en la sociedad civil" (Oszlak y O’Donnell, 1984). En su contenido expresa la existencia de tomas de posición por parte de las diferentes agencias, organizaciones e instancias del aparato estatal y su interacción con diferentes sectores y grupos sociales. En el caso de las políticas habitacionales, la modalidad de intervención del Estado está referida al plano de la vivienda o hábitat según cómo sean enfocadas. Y por lo tanto, se presentan como "un conjunto de acciones y omisiones que manifiestan en forma concreta la intervención del Estado en relación a la distribución/localización de los diferentes sectores y grupos sociales en la ciudad y, concomitantemente, en relación a la satisfacción de necesidades habitacionales básicas" (Oszlak, 1991. En: Rodríguez et al; 2007: 24).

El análisis que planteamos de estas políticas se refiere a una indagación en torno a cómo a partir del desarrollo de ciertas políticas se da un proceso de dominio más de tipo técnico-político y económico en el cual se realiza un ordenamiento del espacio; y por lo tanto, se construye un determinado territorio. Esta propuesta no significa confundir el territorio con un sustrato material sino, por el contrario, analizar cómo se proyectan y se producen relaciones de poder, cómo es construido el territorio funcionalmente y cómo es producido el espacio urbano en la ciudad.

\section{LA CIUDAD Y LOS SECTORES POPULARES}

La ciudad, sus espacios en tensión y en disputa ponen en evidencia la problemática del acceso al suelo urbano, al techo (una vivienda) y a la vida urbana que vivencian los sectores populares. De forma general, los diversos estudios sobre sectores populares han vinculado el término con la clase obrera o los trabajadores. Es decir, relacionado directamente con aquellos sujetos que se encuentran dentro de la estructura de producción y las relaciones productivas. Como plantea Romero $(1997,1987)$, los sectores populares no sólo comprenden a la clase obrera sino que existe una amplitud a otros grupos que no se confunden con ella, pero que tampoco pueden ser totalmente separados de ella. En el caso de las sociedades latinoamericanas, la definición de los sectores populares se ha ampliado y ya no comprende únicamente al movimiento obrero. Tiene límites menos precisos incluyendo tanto a empleados, comerciantes y ciertos profesionales, como también aquellos comprendidos dentro de las llamadas "economías informales"; habiéndose ampliado también los ámbitos y esferas de interés incluyendo las condiciones de vida fuera del trabajo, vivienda, salud, educación, 
organización entre otros (Romero, 1987). Se presenta como un desafío indagar en definiciones de los sectores populares urbanos y la producción y apropiación del suelo urbano desde y para ellos.

\section{URBANIZACIÓN Y POLÍTICAS DEL ESTADO EN CÓRDOBA}

Diversos autores y direcciones de la municipalidad de Córdoba (Terzaga, 1963; Iróz, 1991, Dirección de Urbanismo, 2000; Dirección de Catastro, 2008) distinguen tradicionalmente cuatro grandes períodos en el crecimiento del área urbanizada de la ciudad. El primero, abarca de 1573/1579 con el primer trazado de las manzanas fundacionales y fines del S.XIX. El período está caracterizado por un crecimiento lento de la ciudad, logrando superar a fines del período el trazado fundacional de la ciudad con la conformación de los denominados Barrios Pueblos. El segundo período, es desde finales del S.XIX hasta mediados del S.XX. Aquí es donde se consolidan los barrios tradicionales y se comienzan a extender. La población supera, entonces, el medio millón de habitantes El tercer período, se corresponde con la segunda mitad de S.XX. En éste se comienza a dar un crecimiento del área urbanizada de forma discontinua hacia la periferia, pero con bajas densidades y dado por una subdivisión de tierras. Se presenta un gran crecimiento poblacional que hace característico al período. "Entre 1940 y 1960 se produce una importante urbanización, como proceso paralelo de la industrialización, la que determinó rasgos y problemas de la estructura urbana de la ciudad, caracterizada principalmente por una amplia extensión del área urbanizada a bajas densidades edilicias y de población, con fraccionamiento de tierras sin servicios y sin ocupación de las mismas; así como la ocupación de diversos terrenos sin los servicios adecuados" (Dirección de Catastro, 2008). El cuarto período, se refiere a las transformaciones urbanas actuales desde las últimas tres décadas y está caracterizado por una desaceleración en el crecimiento poblacional y nuevos patrones de localización y uso del suelo en las actividades residenciales y comerciales. Las transformaciones son mayormente de tipo cualitativo. 
Imagen II. Crecimiento urbano de la ciudad de Córdoba

(1810

Fuente: Terzaga, 1963 y Dirección de Urbanismo-Municipalidad de Córdoba, 2000. En: "La ciudad de 1894 y la ciudad de 2008. Transformaciones en la ciudad desde 1894, fecha del último revalúo". Dirección de catastro, Municipalidad de Córdoba. Pág. 5.

Respecto a las políticas y decisiones que ha tomado el estado, en este caso el municipal, respecto a la regulación del uso y ocupación del suelo en la ciudad; retomamos el documento "La ciudad de 1894 y la ciudad de 2008. Transformaciones en la ciudad desde 1894, fecha del último revalúo" realizado por la Dirección de catastro de la Municipalidad de Córdoba, a los fines de recuperar desde el propio discurso y práctica estatal las políticas y ordenanzas que identifican como de regulación del territorio. Dicho documento expresa que en 1985, de forma paralela al desarrollo de diversas obras públicas, se sistematizaron nuevas ordenanzas urbanísticas que otorgaron nuevas reglas y certidumbres al proceso urbanizador. Entre ellas, hay cuatro normativas que son las principales para la regulación de la ciudad y el ordenamiento territorial.

1. Ordenanza № $8060 / 85$ y modificatorias regulan el fraccionamiento del suelo en el ejido de la ciudad, 
2. Ordenanza № 8057/86 y modificatorias regulan la ocupación del suelo en el Área Central,

3. Ordenanza № 8256/86 y modificatorias regulan la ocupación del suelo en Áreas intermedias y periféricas,

4. Ordenanza № 8133/85 y modificatorias regulan la localización de las actividades económicas que impliquen uso del suelo industrial o asimilable al mismo.

5. Ordenanza № 8248/85 Regula la Preservación del Patrimonio Cultural y Arquitectónico Urbanístico

A partir de éstas y teniendo en cuenta nuevas modalidades residenciales y comerciales se realizaron diversas ordenanzas modificatorias y adaptaciones de las normativas urbanas. Entre ellas, la ordenanza № 8606/91 se estableció una normativa para regular lo que fue denominado como Urbanizaciones Residenciales Especiales (countries), con la Ordenanza № 10.761 se creó la zona N1 destinada a urbanizaciones rurales de baja densidad y por Decreto Reglamentario № 25/98 se establecen pautas para loteos impulsados por mutuales, cooperativas y otras entidades intermediarias sin fines de lucro para ejecución de planes de vivienda económica.

La Ordenanza № 12077 y su modificatoria regulan los convenios urbanísticos y las concertaciones público-privadas sobre el uso del suelo. Siendo ésta un mecanismo de negociación entre el municipio y los denominados desarrollistas urbanos.

Con la puesta en vigencia de las distintas normativas se registraron nuevas tipologías de urbanizaciones. En veintitrés años (de 1984 a 2007), en la ciudad se incorporaron 5.516 ha. nuevas al área urbanizada; representando para el año 2007 el 38\% de la superficie total del ejido municipal. Esta nueva superficie de la ciudad se corresponde tanto a usos residenciales como comerciales, industriales e institucionales.

Según datos de la Dirección de Catastro, en lo que respecta al uso de tipo residencial, para el mismo período, se presentaron incorporaciones de nuevas urbanizaciones tanto al interior del área urbanizada de la ciudad como en nuevas extensiones alcanzando una superficie de 4493 ha. Cifra que incluye lo materializado y en proceso de materialización (Ver tabla I). 
Tabla I. Urbanizaciones tramitadas en el período 1985-2008

\begin{tabular}{|lrr|}
\hline \multicolumn{3}{|c|}{ URBANIZACIONES TRAMITADAS 1985 - 2008 } \\
\hline Tipo de Urbanización & Hectáreas & $\%$ \\
\hline Planes de Vivienda (1) & 1.647 & $37 \%$ \\
URE (2) & 1.074 & $24 \%$ \\
Loteos sin Plan de Vivienda & 870 & $19 \%$ \\
Villas y loteos fraudulentos & 452 & $10 \%$ \\
Plan Nuevos Barrios (3) & 282 & $6 \%$ \\
Loteos Rurales (4) & 93 & $2 \%$ \\
Complejos Cerrados & 76 & $2 \%$ \\
Totales & 4.493 & $100 \%$ \\
\hline (1) Planes de vivienda provinciales, municipales, de cooperativas de vivienda y privados. \\
(2) URE: Urbanización Residencial Especial (Countries) regulados por la Ordenanza 8606/91. \\
(3) Urbanizaciones del Plan Nuevos Barrios / Mi Casa Mi Vida del Gobierno Provincial. \\
(4) Urbanizaciones residenciales rurales en la zona N1 de la Ordenanza 8256/8. \\
\hline
\end{tabular}

Fuente: cálculos propios según información provista por la Dirección de Planeamiento Urbano Municipalidad de Córdoba, cartografía oficial de la ciudad de Córdoba e imagen satelital Quick Bird, Junio. En: "La ciudad de 1894 y la ciudad de 2008. Transformaciones en la ciudad desde 1894, fecha del último revalúo". Dirección de Catastro, Municipalidad de Córdoba.

\section{EL CORRELATO TERRITORIAL DE LAS POLÍTICAS HABITACIONALES Y URBANAS}

Como se puede apreciar en el apartado anterior, a escala local el territorio o lo territorial es un aspecto de importancia en las políticas públicas; como tal, con la implementación de dichas políticas va a producirse un correlato territorial de éstas. Las normativas y regulaciones establecidas sobre fraccionamiento, localización, uso y ocupación del suelo en la ciudad han dado como resultado toda una gama de transformaciones socioterritoriales. Las ordenanzas de urbanizaciones residenciales especiales, posibilitaron una nueva modalidad y tipología de residencia (countries, urbanizaciones rurales y complejos cerrados) que, de acuerdo a los datos de la Dirección de Catastro, pasaron a ocupar el 28\% de la superficie. En contrapartida de ello, en los últimos años sólo fue destinado un $6 \%$ de superficie a programas de vivienda social.

Cabe destacar, que tanto las nuevas modalidades de residencia como las de vivienda social han tenido mayoritariamente localizaciones en la periferia de la ciudad. En el caso de los countries y complejos residenciales cerrados, su localización ha sido principalmente hacia el 
noroeste de la ciudad y en sudoeste. Y las viviendas sociales bajo el programa provincial "Mi casa, mi vida", fueron localizadas principalmente en el sudeste de la ciudad y algunos en el noreste y noroeste.

La Ordenanza № 8133/85 que regula la localización de actividades económicas que implican uso de suelo industrial y la № 9843/98 que acuerda una serie de pautas para la localización y requisitos funcionales de nuevas grandes superficies comerciales, también han tenido su correlato en las transformaciones socioterritoriales de la ciudad. En los 90’ proliferan diversos establecimientos con grandes superficies destinadas a comercio como lo son los denominados "shopping centers" e hipermercados mayoristas y minoristas, teniendo un gran impacto tanto en las áreas donde fueron localizados como en las tradicionales áreas comerciales de la ciudad (Dirección de Catastro, 2008).

Con las Ordenanzas de concertaciones público-privadas y la modificatoria de convenios urbanísticos, se posibilitaron nuevas transformaciones urbanas en la ciudad. Estos nuevos convenios entre el municipio y privados, se aplican a grandes proyectos inmobiliarios; se autorizan/habilitan permisos de edificación mediante excepciones a las normas que regulan el uso y ocupación del suelo a cambio del beneficio de una contraprestación -del 10\% aproximadamente de los metros cuadrados cubiertos resultantes de la excepción- a ser retribuida en obras públicas, tierras o efectivo los cuales irían a un fondo especial para infraestructura u obras del presupuesto participativo.

Acorde a esta norma, el capital privado -en especial el de las grandes empresas de la construcción que conforman la Cámara Empresarial de Desarrollistas Urbanos de Córdoba (CEDUC)- pasa a tener un poder mayor en la reconfiguración del espacio urbano y de los nuevos usos y ocupación del suelo en la ciudad.

Las nuevas condiciones que ofrecen estos marcos regulatorios municipales han repercutido en las formas diferenciales de acceso al suelo urbano. "Los territorios no son una simple proyección espacial de las iniciativas públicas, sino que son una construcción social, que condensan acciones y comportamientos múltiples, acumulados en el tiempo, con capacidad de influir también de forma significativa sobre el desarrollo de la política en un sistema de retroalimentación dialéctico" (Rodríguez y Di Virgilio, 2011: 18).

\section{ESPACIOS EN DISPUTA Y ACCESO DE LOS SECTORES POPULARES AL SUELO URBANO}

Como se mencionó al principio, la producción de la ciudad capitalista es resultado de una interacción compleja y contradictoria de diversas lógicas que a los fines analíticos pueden 
agruparse en las siguientes: la de la ganancia, la de la necesidad y la de lo público. Esto implica procesos, ritmos, estrategias y actores que pueden ser diferenciados acorde a sus objetivos, intereses y prioridades; y cuyas prácticas pueden ser vinculadas a una determinada lógica. Como plantean Rodríguez et al (2007), la producción de la ciudad involucra materialmente un conjunto de infraestructuras, soportes y equipamientos que permiten el despliegue de diversos usos y actividades, residencial, comercial, industrial, servicios, entre otros que hacen a la vida urbana y al habitar la ciudad. La ciudad y su producción comprenden un entramado de complejos procesos sociales, políticos, económicos y culturales. Esto quiere decir, que es tanto multiescalar como multidimesional y temporal. Conflictos y disputas en torno al espacio urbano poseen actores en pugna que compiten por usos y formas de apropiación-dominación del espacio.

La ciudad formal se vincula a un determinado orden urbano, a un conjunto de reglas normas- que remiten a diversos niveles del derecho positivo y que en su carácter formal poseen un conjunto variado de normas jurídicas que están orientadas tanto a la regulación de la apropiación del suelo, sus usos y la producción de la ciudad (derechos de propiedad, normas de planeamiento, de construcción, entre otras), como a la regulación de las prácticas urbanas (Duhau y Giglia, 2004) "permitidas". En lo instituido como formal está implícito el reconocimiento y reproducción de una lógica hegemónica de producción del espacio y de forma de acceso al suelo urbano directamente asociado a la propiedad privada y al mercado mayoritariamente. La ciudad contemporánea es producto del funcionamiento del mercado del suelo que produce una estructura de ciudad (Jaramillo, 2003) que niega la existencia de otras lógicas y dinámicas de producción, ubicándolas al margen de lo reglado o instituido. Y como tal, deja de lado otros conocimientos, otros saberes, prácticas, experiencias y vivencias de la vida urbana.

A escala local, en el caso de la ciudad de Córdoba, las políticas habitacionales destinada a los sectores populares son mayoritariamente focalizadas en el desplazamiento de los sectores económicamente más pobres hacia localizaciones periféricas por fuera del anillo de la Av. de Circunvalación. En el año 2001, como efecto de la crisis económica y financiera, así como de las transformaciones estructurales implementadas en los $90^{\prime}$, se registró un aumento en la cantidad de asentamientos que desde la normativa municipal se consideran irregulares (Boito. et al, 2009), así como el crecimiento de la población residente en éstos y en villas. Proceso, que se podría relacionar con la dificultad creciente para los sectores económicamente más pobres de poder acceder al suelo urbano mediante las condiciones del mercado formal. La población que no puede acceder ni satisfacer sus necesidades habitacionales dentro del marco de la 
normativa municipal de regularidad urbana, va a tomar como estrategia y alternativa de acceso al suelo urbano, el ocupar o tomar tierras sin utilización con el fin de dedicarlas a la autoconstrucción de viviendas.

En el año 2011, el Observatorio Urbano Córdoba (OUC) de la UNC en forma conjunta con la Municipalidad de Córdoba llevaron a cabo un proyecto en el que se geo-referenciaron, en un mapa, situaciones de irregularidad urbano dominial en la ciudad de Córdoba Capital; en éste se puede observar que entre las categorías villas, asentamiento, urbanización de producción estatal, urbanización producida por organización comunitaria, loteo ilegal y loteo iniciado por organización comunitaria suman aproximadamente un total de 340 asentamientos para y de sectores populares.

Mapa 1. Asentamientos populares

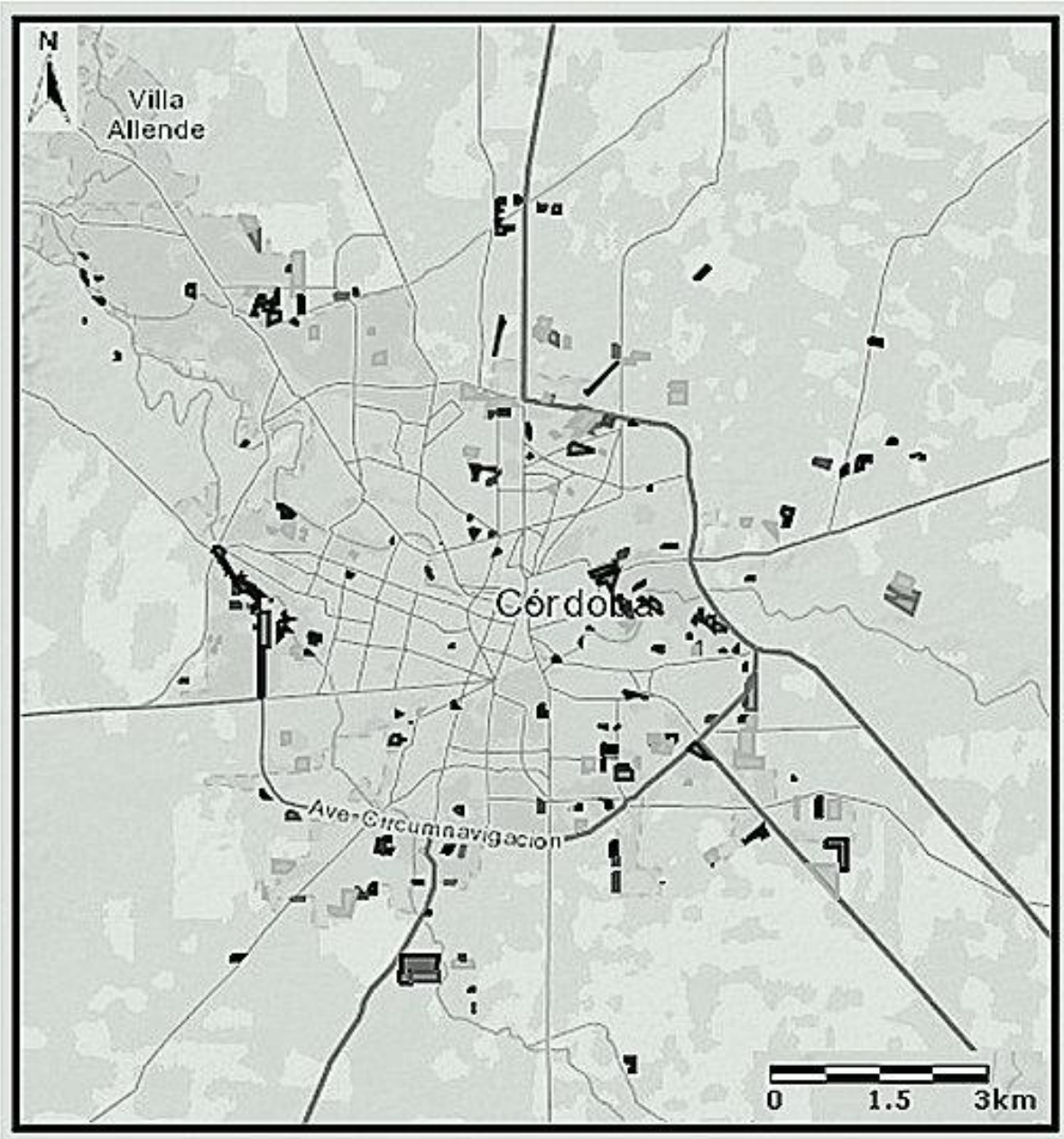

Fuente: Imagen de Mapa de Irregularidad Urbano Dominial Córdoba Capital- OUC/UNC. 
Mapa 2. Urbanizaciones de producción estatal

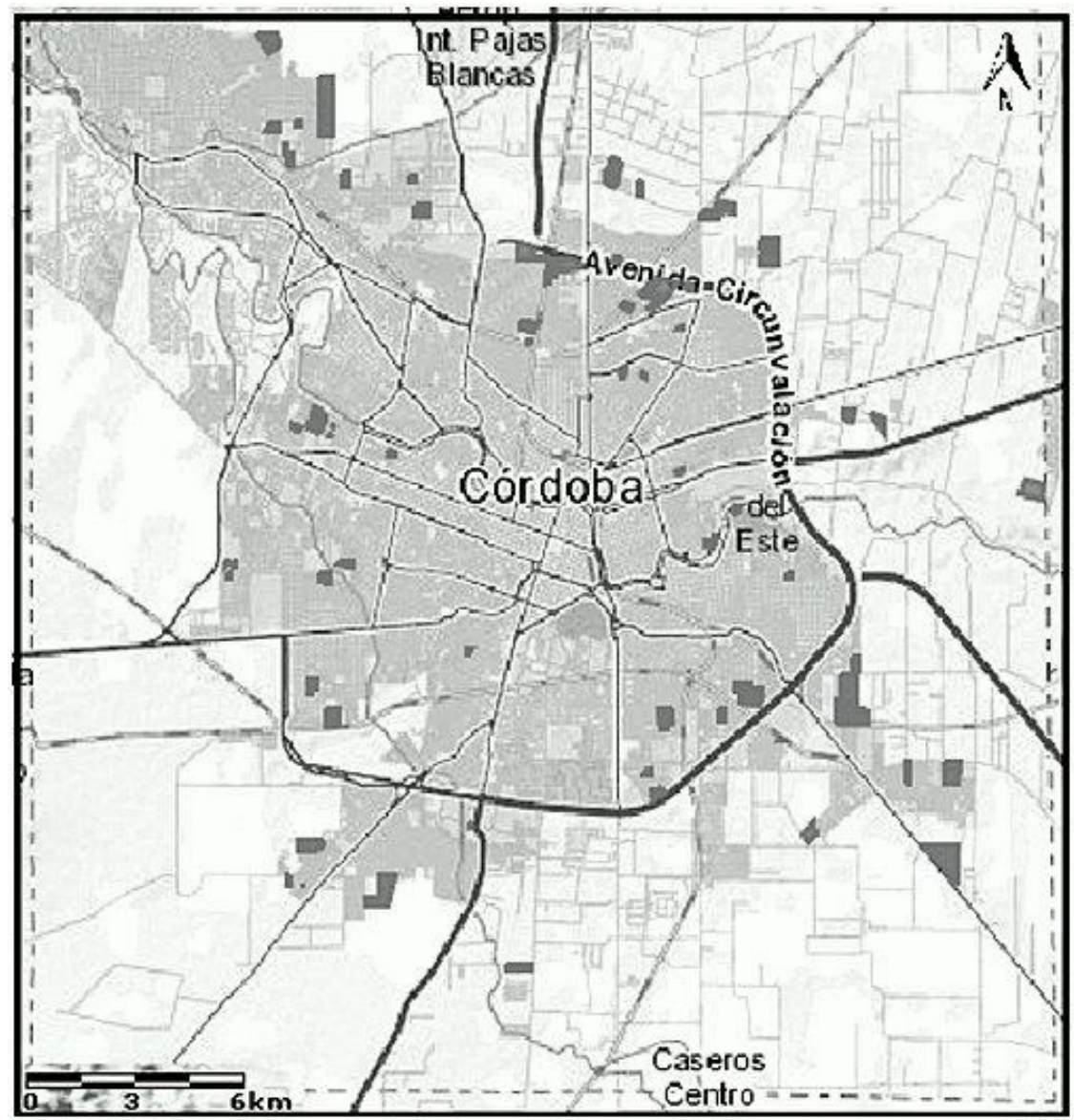

Fuente: Imagen de Mapa de Irregularidad Urbano Dominial Córdoba Capital- OUC/UNC

Como contraparte de estos procesos, la construcción inmobiliaria en el marco del mercado formal ha adquirido una centralidad en la absorción de excedentes productivos. En la ciudad de Córdoba, uno de los principales fondos económicos para los desarrollos inmobiliarios son los excedentes de capital producidos en el marco del patrón productivo extractivistarentista ${ }^{5}$.

\footnotetext{
${ }^{5}$ Al hablar de complejo extractivo-rentista, Féliz y López (2010) hacen referencia a que «...esas ramas se basan fundamentalmente en la extracción de recursos no renovables de manera directa (minería) o indirecta (agricultura y ganadería intensiva). En ambos casos, circunstancias geográficas e históricas hacen que en Argentina esa producción y sus manufacturas primarias (mayoritariamente commodities) generen rentas extraordinarias» (Féliz et al.2010).
} 
La reestructuración económica mundial actual, reconoce formas en el espacio y en el territorio a través de las cuales se les posibilita la valorización y acumulación de capital (Harvey, 2008). En las ciudades, ello se traduce en una expansión (tanto en vertical como en horizontal según la zona) y un crecimiento de la actividad inmobiliaria en distintas áreas que se vuelven polos de atracción para las inversiones y especulaciones del mercado inmobiliario guiada bajo la lógica de la ganancia. En el caso de Córdoba, se pueden reconocer como algunas de estas áreas: el área central y peri-central (Bo Centro, Nueva Córdoba, Observatorio, Güemes, Alberdi, General Paz, San Vicente, entre otros), Costanera del Río Suquía, algunos sectores de la zona sur y la zona noroeste de la ciudad (particularmente sobre las principales vías de acceso y conexión a la ciudad).

El Estado a través del despliegue de políticas de competitividad urbana, pasa a poseer un rol más activo en el espacio urbano a la par del favorecimiento de los intereses de los sectores de mayor poder adquisitivo. En este marco y en concordancia con un incremento de los precios del suelo urbano, nuevos actores comienzan a desplegar sus actividades (bajo una lógica de captura de ganancias y rentabilidad) y a tener un rol más activo; entre ellos encontramos a: inversionistas, empresas constructoras, desarrolladores urbanos e inmobiliarios, asesores profesionales y de marketing. Paralelamente, otras zonas de la ciudad sufren procesos de profundización de la degradación que poseían con anterioridad. Se convierten en zonas con un alto grado de déficit en materia de infraestructura, servicios y equipamientos, aledañas a zonas con alto grado de contaminación ambiental, con superposición de usos del suelo: residencial, industrial y agrícola, entre otros aspectos; justamente en éstas es donde el Estado ha tenido un rol activo como productor de viviendas sociales a través de diversos planes y programas habitacionales, aunque mayoritariamente no ha mejorado las condiciones materiales de infraestructura, equipamientos y prestación de servicios, ni tampoco ha modificado la normativa de ocupación y uso del suelo. Es allí también donde se encuentran localizados asentamientos populares de diversas tipologías (Cisterna et al, 2012).

En la ciudad y el espacio urbano se presentan conflictos y disputas por los espacios, por su uso, organización y consumo. En el mapa que se presenta a continuación, se puede observar como la lógica de la ganancia avanza hacia el centro, noroeste y suroeste de la ciudad desplazando y presionando a las otras lógicas a espacios o zonas cada vez más periféricas. La ciudad se convierte en un objeto y soporte para el despliegue de diversos negocios, entre ellos los inmobiliarios. Mientras que la lógica de la necesidad y lo público queda relegada a los espacios intersticios de la ciudad y a la periferia propiamente. 
Mapa 3. Zonas de avance y desarrollo inmobiliario de mercado formal

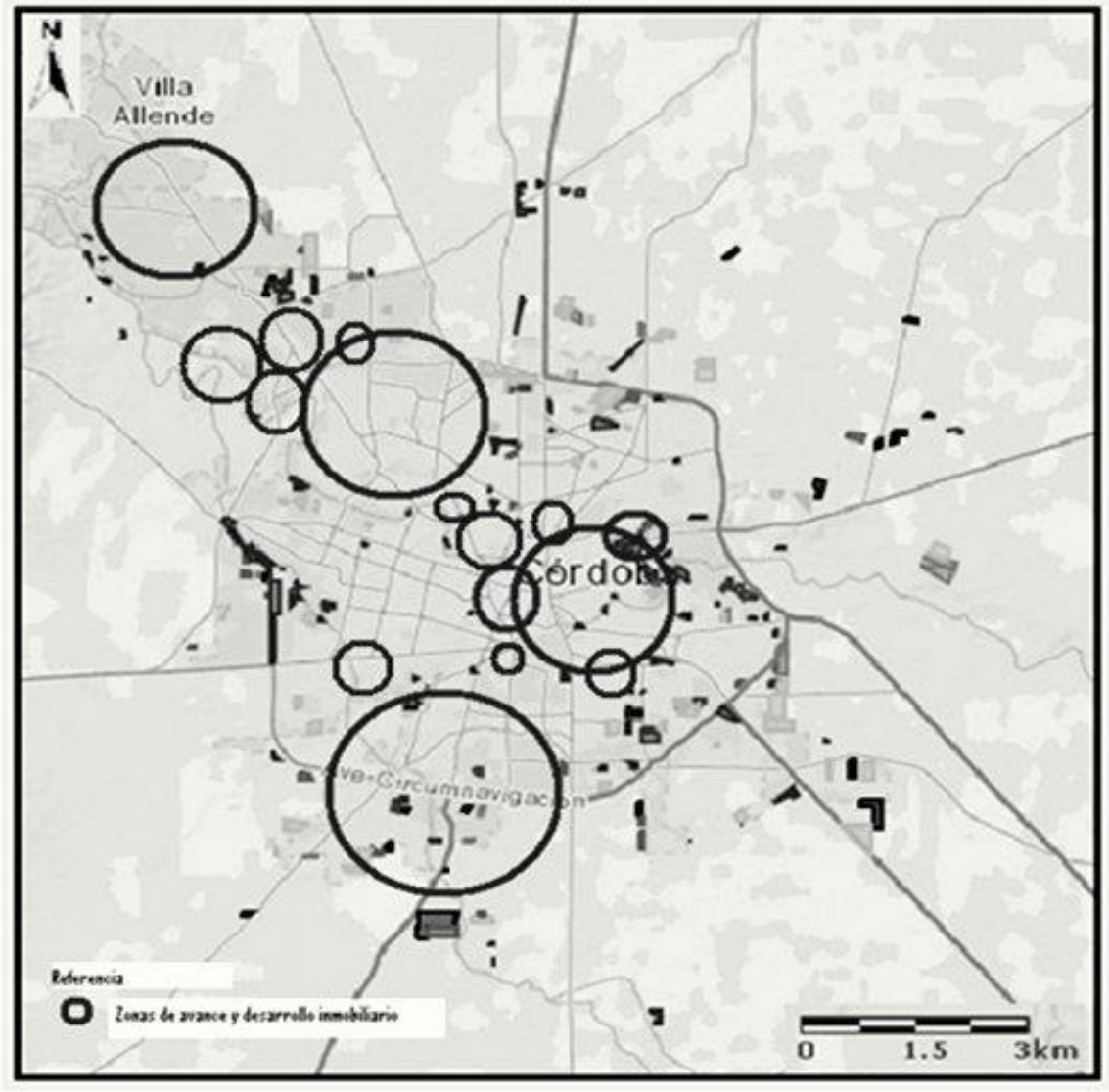

Fuente: Elaboración propia sobre base mapa 1.

\section{CONCLUSIONES}

El entretejido de lo global y lo local es importante en el análisis para comprender como se va produciendo y entramando el contexto histórico en las disputas por el espacio urbano. Como plantea Massey (2012) "en este momento de crisis el espacio y el lugar son muy importantes no sólo en el análisis de la situación social y económica, sino también para pensar políticamente la coyuntura1 actual y el modo de salir de ella" (Massey, 2012: 3). 
La espacialidad del capitalismo en la ciudad implica que tanto espacios como territorios urbanos no sólo son disputados por el capital, sino también por otros actores y grupos que no siempre coinciden con la lógica de acumulación de este modelo dominante. La materialización de las rentas de suelo urbano en pos de la incesante acumulación de capital gesta un constante crecimiento urbano en conflicto y disputa por lo espacios en la ciudad, ello pone de manifiesto las contradicciones de las relaciones sociales y políticas de acceso al suelo por determinados sectores. Como contraparte de la libre competencia para el capital en la ciudad, se produce la exclusión al acceso al suelo urbano por parte de los sectores populares. Al decir de Lefebvre (1974ạ), el espacio abstracto de los expertos (urbanistas, planificadores, técnicos, etc.) es contradictorio al espacio concreto, aquél de los "sujetos" y de las actividades cotidianas.

El espacio dominado por el rigor técnico-funcional y la apetencia de beneficios del capitalismo, aprovechan las condiciones de rentabilidad que los territorios y lugares brindan. La transformación de los espacios urbanos desempeña un papel central en la economía global y la ciudad se vuelve el locus de proyectos urbanos que benefician a empresas de construcción y urbanismo. La disputa por los espacios es parte de este proceso.

Nos encontramos hoy, en la ciudad de Córdoba, ante la emergencia de una configuración espacial regida mayoritariamente por un orden urbano que prioriza la ciudad como un "negocio". Ello ha producido y produce una profundización de las desigualdades socioespaciales Las últimas políticas habitacionales y urbanas, en vez de haber reducido estas desigualdades han ampliado las diferencias espaciales de forma negativa aumentando el conflicto y la disputa por el espacio urbano. Bajo el lema del progreso y desarrollo para la ciudad, se piensa un solo tipo de ciudad y un orden urbano acorde a las necesidades de los grupos hegemónicos y de mayor poder adquisitivo. En el ámbito de las políticas habitacionales y urbanas (específicamente de vivienda), el estado ha redefinido su papel en concordancia con una mayor presencia del mercado. De esta forma, se fortalece una tendencia al favorecimiento de intereses de tipo privado en la producción, planeamiento y regulación de la ciudad. La lógica de producción de espacio urbano predominante es la de la ciudad como mercancía de reproducción capitalista. Si bien, se han llevado a cabo e implementado leyes, programas, planes y proyectos desde el estado provincial para la provisión de viviendas, regularización dominial de tierras y saneamientos de títulos, escrituración gratuita de viviendas sociales, entre otras. La inclusión de los sectores populares en la ciudad se realiza en concordancia con el postulado de una inclusión perversa; en pos de una inclusión social y urbana se les niega -entre otros aspectos- la centralidad, se los relega a espacios con altos grados de deterioro y riesgo ambiental, se los relocaliza en espacios desarticulados de otros espacios y en donde no cuentan 
con redes sociales anteriores que garantizaban su reproducción social. A la vez, esta supuesta inclusión se sustenta de forma jurídica mayoritariamente en la propiedad privada e individual del suelo urbano y vivienda, no dando lugar a la posibilidad de otras formas de propiedad como son las de propiedad colectiva u otras modalidades de tenencia y propiedad. La orientación de las intervenciones del estado en materia políticas habitacionales y urbanas hacía sectores populares en la ciudad de Córdoba, ha priorizado el carácter netamente material (provisión de vivienda como unidad física); al mismo tiempo que ha colocado a la población como mera beneficiaria y no ha comprendido una visión integral del hábitat, ni ha garantizado la accesibilidad al suelo urbano para los sectores populares desde el reconocimiento a otras lógicas de producción del hábitat y espacio urbano. La lógica estatal respecto a la producción del espacio urbano produce espacios separados y diferenciados de la ciudad, donde la mayor parte de las veces influyen negativamente en la apropiación posterior de los pobladores.

Las distintas lógicas de producción del espacio urbano se encuentran en conflicto, tensión y disputa por los espacios en la ciudad, siendo la lógica de la ganancia la que detenta espacios a los fines de especulación inmobiliaria o el uso para el despliegue de diversos negocios que otorgan grandes beneficios económicos y rentabilidad. Y que se ve fortalecida con el despliegue de diversas políticas estatales como las de competitividad urbana que favorecen a la lógica de la ganancia, siendo alguno de los ejemplos de ello la refuncionalización de la ex cárcel del Buen Pastor (sitio de la memoria por lo sucedido durante la dictadura militar [19761983] localizado en el barrio de Nueva Córdoba y que actualmente es un espacio de ocio y comercio lleno de locales y tiendas) o el nuevo proyecto de refuncionalización de la ex cárcel de Encausados (UCA) que pasará a ser un centro cultural, comercial y residencial con módulos habitacionales que se denominará Paseo Güemes.

Como plantea Smith (s/a)

"No solo está la recalificación urbanística de zonas del centro de la ciudad y los diversos enclaves y complejos enriquecidos por inversiones de capital y negocios en contraste con los crecientes barrios chabolistas. Esa existente dualidad geográfica económica de la ciudad contemporánea se ha intensificado, pero también ha sido petrificada por la infusión política de un nuevo régimen de seguridad. Ciudades valladas, enclaves y urbanizaciones para ricos junto a una floreciente seguridad privada y transporte seguro son la norma para cada vez más urbanitas ricos; aumento de policía patrullando el espacio público, vigilancia, represión y la militarización de las patrullas de vigilancia donde no estaba militarizada anteriormente son las nuevas normas para muchos de los pobres. Esos son obviamente los signos geográficos de una incisiva realidad 
social, es decir, que los niveles de desigualdad entre los ricos y los pobres se han expandido dramáticamente en las últimas dos o tres décadas" (Smith, s/a: 24 y 25).

La creciente mercantilización del suelo urbano restringe a amplios sectores de la población al acceso a la vivienda y a la vida urbana. El aumento del precio de los alquileres junto con el creciente déficit habitacional existente en el país, y sumado a ello, los salarios, inflación y dificultad en el acceso a empleos formales, hace insostenible la accesibilidad a la vivienda y a hábitat urbano para muchos sectores de la población. Frente a esta situación, y mediante un importante proceso de organización social, la toma de tierras se torna cada vez más una alternativa posible y legítima de solución, convirtiéndose en un proceso de urbanización en auge y crecimiento en los últimos 10 años.

El propósito de este trabajo fue generar algunas breves reflexiones en torno a las lógicas de producción del espacio urbano en la ciudad de Córdoba. Y poner de manifiesto, que el abanico de situaciones -toma de tierras y los asentamientos- en las que los sectores populares acceden a la ciudad pueden ser consideradas como un proceso de producción del espacio urbano, que al ser sostenidas en la organización popular y territorial, y a través de reivindicar el derecho a la vivienda, ponen en cuestión el actual modelo de producción del espacio urbano dominante; y por lo tanto mediante su accionar inician su ejercicio al derecho a la ciudad (Pedrazzani, 2014).

La constitución provincial de Córdoba expresa en su artículo 58: "Todos los habitantes tienen derecho a disfrutar de una vivienda digna, la que, junto a los servicios con ella conexos y la tierra necesaria para su asentamiento, tiene un valor social fundamental. La vivienda única es inembargable en las condiciones que fija la ley.

El Estado Provincial promueve las condiciones necesarias para hacer efectivo este derecho. A tal fin planifica y ejecuta la política de vivienda y puede concertarla con los demás niveles jurisdiccionales, las instituciones sociales o con el aporte solidario de los interesados. La política habitacional se rige por los siguientes principios:

1. Usar racionalmente el suelo y preservar la calidad de vida, de acuerdo con el interés general y pautas culturales y regionales de la comunidad.

2. Impedir la especulación.

Asistir a las familias sin recursos para facilitar su acceso a la vivienda propia.

El interrogante que nos podemos realizar aquí, es:

¿Cuáles son los espacios que se les permite disputar a los sectores populares y es posible seguir reproduciendo y legitimando un solo orden urbano en nuestras ciudades? 
Consideramos que es preciso repensar desde diversos ámbitos (académicos y no académicos, estatales y no estatales, públicos y privados) y saberes en diálogo una redefinición del rol del estado en general, pero específicamente en lo que respecta al desarrollo urbano de las ciudades, al mercado del suelo (formal e informal) y su regulación y a políticas de suelo que permitan disminuir las desigualdades sociales.

Como Abramo, recuperamos la política urbana -y la habitacional- como un elemento clave y un instrumento institucional desde el que se puede apaciguar el libre juego y fuerzas del mercado y su cultura mercantil. Y desde la cual se puede ampliar el derecho a la ciudad (Abramo, 2006: 181).

Ahora, es de gran importancia tener cuidado al reivindicar el derecho a la ciudad. Este derecho:

Es un significante vacío. Todo depende de quién lo llene y con qué significado. Los financieros y promotores pueden reclamarlo y tienen todo el derecho a hacerlo; pero también pueden hacerlo los sin techo y sin papeles. Inevitablemente tenemos que afrontar la cuestión de que derechos de ben prevalecer, al tiempo que reconocemos, como decía Marx en El Capital que «entre derechos iguales lo que decide es la fuerza». La definición del derecho es en sí mismo objeto de una lucha que debe acompañar a la lucha por materializarlo. (Harvey, 2012: 13).

El planteamiento que realiza Mitchell (2012) acerca de las tiendas en las ciudadescampamento en Estados Unidos, consideramos que puede ser planteado también respecto a las urbanizaciones populares en América Latina y el Caribe. Estas urbanizaciones (villas, asentamientos populares con origen en tomas de tierra, etc)

Dejan claro que la ciudad es una ciudad capitalista - una ciudad violenta y destructiva, precisamente la ciudad de la que hablaba Engels hace más de ciento cincuenta años cuando dijo que la burguesía no tenía más solución al problema de la vivienda que desplazarlo...que el refugio ofrecido para la mayoría por y en la ciudad capitalista no puede ser sino igualmente endeble, igualmente sujeto a ser desmantelado, destruido, y su valor de uso destrozado. Esto se conoce como: desalojo, embargo, gentrificación y otros términos en apariencia menos violentos. (Mitchell, 2012: 17).

La transformación del orden imperante en la ciudad es la lucha cotidiana por reformar las normas que segregan a los sectores populares del acceso al suelo urbano y el derecho a la ciudad, del mejoramiento de su situación, de su habitar la ciudad.

¿Cuál es el miedo, entonces, de aceptar las urbanizaciones populares como un modo de producción legal, regular en la ciudad? 
Que estas formas de urbanización en la ciudad, que son producidas por las relaciones capitalistas de producción y acumulación, pueden llegar a ser un germen con poder que no obedece necesariamente a esa relaciones y podría atentar a ellas e intentar derrocarlas (Mitchell, 2012). Actualmente en la ciudad de Córdoba nos encontramos ante la emergencia y fortalecimiento de diversas prácticas y experiencias vinculadas a diversos grupos sociales que emergen y comienza a protagonizar la escena política a partir de sus vivencias desde el hábitat popular y en la ciudad, grupos que desde otros epistemes y lugares de enunciación recuperan la diferencia y diversidad como elementos centrales en la conformación de las identidades y territorialidades que hacen a su vida cotidiana en lo urbano. Habrá que ver a futuro el poder que tomen y su injerencia en la definición de nuevas políticas y alternativas al orden establecido. Entonces, como plantea Porto Gonçalves, el mayor desafío que tenemos desde los ámbitos académicos es el no apartarnos de la propia práctica, del codo a codo y mano a mano con la gente y los lugares. Es necesario fortalecer y legitimar en la academia un discurso desde el lugar o el espacio y no sobre el lugar y/o espacio. Y desde y sobre indica dos formas muy distintas de construcción de conocimiento.

\section{BIBLIOGRAFÍA}

ABRAMO, Pedro (2006) Ciudad caleidoscópica. Una visión heterodoxa de la economía urbana. Ed. Gesbiblo. España.

(2009) La producción de las ciudades Latinoamericanas: mercado inmobiliario y estructura urbana. Ed. OLACCHI. Ecuador.

BOITO, María Eugenia; CERVIO, Ana Lucía; ESPOZ DALAMSSO, María Belén (2009): "La gestión habitacional de la pobreza en Córdoba: el antes y después de las 'Ciudades-Barrios'". Boletín Onteaiken № 7, mayo. S/L. www.accioncolectiva.com.ar

CISTERNA, Carolina; MONAYAR, Virginia; PEDRAZZANI, Carla (2012) "Transformaciones del espacio urbano en la zona noroeste de la Ciudad de Córdoba. Un análisis desde la trayectoria temporal del precio del suelo" Ponencia presentada en el Primer Seminario Internacional "Territorio, Desarrollo sostenible, Luchas sociales y Ciudadanía" Universidad Nacional de Villa María. Córdoba

DUHAU, Emilio (2003) "La ciudad informal. El orden urbano y el derecho a la ciudad" [versión para discusión] Congreso de la ANPUR, Belo Horizonte.

DUHAU, Emilio y GICLIA, Ángela (2004) "Conflictos por el espacio y orden urbano". Estudios Demográficos y Urbanos, mayo-agosto, número 056. El Colegio de México, A. C. Distrito Federal, México. PP. 257-288.

(2008) Las reglas del desorden: habitar la metrópoli. Siglo XXI Editores. México.

DIRECCIÓN DE CATASTRO, MUNICIPALIDAD DE CÓRDOBA (2008) "La ciudad de 1984 y la ciudad de 2008. Transformaciones en la ciudad desde 1984, fecha del último revalúo general". 
FÉLIZ, Mariano; LOPEZ, Emiliano (2010): “La dinámica del capitalismo periférico posneoliberalneodesarrollista. Contradicciones, barreras y límites de la nueva forma de desarrollo en la Argentina". Revista Herramientas № 45. Buenos Aires, Argentina.

HARVEY, David (1994) The Social Construction of Space and Time. A relational theory. Geographical Review of Japan Vol. 67 (2), pp. 126-135. [Traducción interna de la cátedra de Epistemología de la Geografía, 2006] (2008)Derecho a la ciudad. S/D. (2012)Ciudades rebeldes. Del derecho a la ciudad a la revolución urbana. Ed. Akal. España.

INDICADORES CIUDADANOS NUESTRA CÓRDOBA 2011. Red Ciudadana Nuestra Córdoba. http:/www.nuestracordoba.org.ar

IRÓS, Guillermo (1991); Desarrollo Urbano: Reflexiones y Acciones. Editorial Municipal de la Ciudad de Córdoba. Córdoba

JARAMILLO, Samuel (2003). Los fundamentos económicos de la participación en plusvalías; preparado para el CIDE Universidad de los Andes y el Lincoln Institute of LandPolicy,

LEFEBVRE, Henri (1969) El derecho a la ciudad. Ediciones Península. Barcelona, España.

LEFEBVRE, Henri (1976) Espacio y Política: El derecho a la ciudad, II. Ediciones Península. Madrid, España.

MASSEY, Doreen (2012) "Espacio, lugar y política en la coyuntura actual". Revista URBAN. Sección Tribuna. NSO4. España.

MITCHELL, Don (2012) "El poder detesta las ciudades-campamento: o la tiranía del espacio abstracto". Revista URBAN. Sección Tribuna. NSO3. España.

OSZLAK, Oscar; O’ DONNELL, Guillermo (1984): “Estado y políticas estatales en América Latina: hacia una estrategia de investigación" En: Para investigar la administración pública. KUIKSBERG, B. y SULBRANDI, J. Compiladores. España.

OSZLAK, Oscar (1991). Merecer la ciudad. Los pobres y el derecho al espacio urbano. HumanitasCEDES. Buenos Aires

PEDRAZZANI, Carla (2014) "La ciudad y los espacios disputados: la lógica de producción del espacio urbano en Córdoba Capital". X Bienal del Coloquio de transformaciones territoriales. Desequilibrios regionales y políticas públicas. Una agenda pendiente. Asociación de Universidades Grupo Montevideo, Universidad Nacional de Córdoba y Prosecretaría de Relaciones Internacionales (UNC). Córdoba, 5, 6 y 7 de noviembre de 2014.

PRADILLA COBOS, Emilio (2009) "La mundialización, la globalización imperialista y las ciudades latinoamericanas" Revista Urbano Territorial Bitácora 15 (2). Universidad Nacional de Colombia, pp. 13-36.

RODRÍGUEZ, María C.; DI VIRGILIO, Mercedes; PROCUPEZ, Valeria; VIO, Marcela; OSTUNI, Fernando; MENDOZA, Mariana; MORALES, Betsy (2007) "Producción social del hábitat y 
políticas en el Área Metropolitana de Buenos Aires". Documentos de Trabajo № 49. IIGG/FSOCUBA. Buenos Aires,Argentina.

RODRÍGUEZ, María C. y DI VIRGILIO, María M (2011) "Coordenadas para el análisis de las políticas urbanas. Un enfoque territorial". En: RODRÍGUEZ, María C. y DI VIRGILIO, María M (2011) [comp.] Caleidoscopio de las políticas territoriales. Un rompecabezas para armar. Ed. Prometeo Libros. Buenos Aires, Argentina.

ROMERO, Luis (1987) "Los sectores populares en las ciudades latinoamericanas del siglo XX: la cuestión de la identidad". Revista Desarrollo Económico, Vol. 27, № 106 julio-setiembre 1987, pp 201-222. Publicado por: Instituto de Desarrollo Económico y Social Artículo URL Estable: http://www.jstor.org/stable/3466979.

(1997) Los sectores populares urbanos como sujetos históricos. Última Década. Centro de Investigación y Difusión Poblacional de Achupallas. Chile.

SMITH, Neil (S/A) ¿Ciudades después del neoliberalismo? S/datos.

SOJA, Edward (1985). "La espacialidad de la vida social: hacia una reteorización transformativa". En: Dereck Gregori y John Urry (eds). Social Relations and Spatial Structures, Londres.

TRIVELLI, Pablo (1982) "Accesibilidad al suelo urbano y la vivienda por parte de los sectores de menores ingresos en América Latina". Revista EURE, Vol. IX - № 26 pp. 7 - 32. Santiago, Chile.

\section{Fuentes}

OBSERVATORIO URBANO CÓRDOBA (OUC). Universidad Nacional de Córdoba. Mapa: Irregularidad urbano dominial Córdoba Capital [consulta: 20 de noviembre de 2012]. http://www.arcgis.com/apps/OnePane/basicviewer/index.html?appid=68c2e9fbe3614c83939ef 5b73444af2d

CONSTITUCIÓN DE LA PROVINCIA DE CÓRDOBA. Boletín Oficial. http://www.ambiente.gov.ar/archivos/web/biblioteca/File/Contituciones/cp_cordoba.pdf

Trabalho enviado em 14 de fevereiro de 2015.

Aceito em 21 de março de 2015. 